\section{Dementia

Dement Geriatr Cogn Disord 2014;37:154-162

\title{
Prevalence of Depression among Recently Admitted Long-Term Care Patients in Norwegian Nursing Homes: Associations with Diagnostic Workup and Use of Antidepressants
}

\author{
Kristina Riis Iden ${ }^{a} \quad$ Knut Engedal $^{c}$ Stefan Hjorleifsson ${ }^{b}$ Sabine Ruths ${ }^{a}$ b \\ ${ }^{a}$ Research Unit for General Practice, Uni Health/Uni Research, and ${ }^{b}$ Department of Global \\ Public Health and Primary Care, University of Bergen, Bergen, and ${ }^{\mathrm{C}}$ Norwegian Centre for \\ Ageing and Health, Oslo University Hospital Ullevaal, Oslo, Norway
}

\section{Key Words}

Depression · Antidepressant medications · Diagnostics · Nursing homes · Admission

\begin{abstract}
Aims: We aimed to establish the prevalence of depression among recently admitted longterm care patients and to examine associations with diagnostic initiatives and treatment as recorded in patients' medical records. Materials and Methods: Eighty-eight long-term care patients were included. Depression was diagnosed according to the ICD-10 criteria; patients were screened for depression using the Cornell Scale for Depression in Dementia (CSDD) and for dementia with the Clinical Dementia Rating (CDR) scale. Results: Depression was found in $25 \%$ of the patients according to the ICD-10 criteria and in $31 \%$ according to a CSDD sum score of $\geq 8$. Diagnostic initiatives were documented in the medical records of half of the patients with depression. Forty-four percent of the patients were prescribed antidepressants and $23 \%$ actually received them for the treatment of depression. Conclusion: Depression was prevalent among recently admitted long-term care patients, but diagnostic initiatives were too rarely used. Antidepressants were commonly prescribed, but depression was the indication for treatment in only half of the cases. Screening for depression should be mandatory on admission.

(C) 2013 S. Karger AG, Basel
\end{abstract}

\section{Introduction}

Depression is prevalent among nursing home patients [1-4] and contributes to reduced quality of life as well as increased morbidity and mortality $[3,5,6]$. The course of depression may be diverse, and treatment should be tailored to patients' individual needs. Drug treatment 
Iden et al.: Prevalence of Depression among Recently Admitted Long-Term Care

Patients in Norwegian Nursing Homes

appears to be most common, while nonpharmacological treatment options like environmental initiatives and psychotherapy are seldom used in nursing homes [7]. Studies show that antidepressant drugs are prescribed to more than every third nursing home patient [8-10]. However, evidence of treatment effectiveness of antidepressant medications is limited in mild and moderate depression and depression in patients with dementia $[11,12]$. Further, antidepressants may increase the risk of falls, hip fracture, hyponatremia and death [13-17]. The prevailing treatment of depression in nursing homes should therefore be reconsidered [18].

Previous research suggests that diagnostics and treatment decisions regarding depression in nursing homes are haphazard and that doctors seldom participate in diagnostic workup and treatment evaluations [19]. Although moving into a nursing home may indicate safety and comprehensive care, it also involves adjustment to a thoroughly different environment and it may imply dependency, loss and mourning [20]. Hence, recently admitted patients may be especially prone to depression, as shown in an Australian study [2].

Therefore, we designed a study to establish the prevalence of depression in patients recently admitted to long-term care (LTC) in nursing homes and to examine associations of depression with diagnostic workup and treatment with antidepressants recorded in patients' medical records.

\section{Materials and Methods}

\section{Nursing Homes in Norway}

In Norway, the municipalities are responsible for the nursing home services. About 40,000 Norwegian citizens live in a nursing home, which corresponds to $18 \%$ of inhabitants aged 80 years and older (Statistics Norway, 2012). Most nursing home doctors are general practitioners (GPs) working part time in these institutions, typically 1 or 2 days per week, although some larger nursing homes have full-time employed doctors. The doctor coverage is on average $0.37 \mathrm{~h}$ per week per patient [21].

\section{Study Population}

Following an information meeting, all 27 nursing homes in 3 municipalities in Rogaland County, Norway, were invited to participate in the study. Institutions that did not attend the meeting were asked by e-mail and phone calls to participate. Eleven nursing homes (24-145 beds) consented to participate. The participating institutions comprised 24 units, i.e. 22 regular units and 2 special care units for patients with dementia. The 11 nursing homes were enrolled consecutively during the study period, from April 2011 to May 2012. Ten institutions participated during the whole study period, and 1 institution was enrolled 2 months before the end of the study.

All recently admitted patients (defined as a stay shorter than 3 months) to LTC in the 24 nursing home units were informed about the study and invited by registered nurses to participate. Patients with an expected lifetime shorter than 3 months were not eligible. The patients were enrolled consecutively throughout the study period. Of 123 eligible patients, 18 declined to participate, 7 did not fulfill the inclusion criteria, 5 withdrew their consent, and 5 were not able to take part in individual interviews due to severe dementia. Finally, 88 patients were included in the study population. If they were competent, they gave their written informed consent themselves. Otherwise, the patients' next-of-kin was asked to provide a written informed consent.

\section{Assessment}

We extracted demographic information from the patients' medical records such as gender, year of birth, marital status, and date of nursing home admittance. Further, we retrieved documentation on any diagnosis of depression and diagnostic initiatives from the medical records, such as: (1) diagnosis codes F41.2 (mixed anxiety and depressive disorder) from the ICD-10 (WHO, Classification System, 1992), and P03 (depressed mood) and P76 (depressive disorder) from the ICPC-2 (International Classification of Primary Care, second edition); (2) diagnostic tests such as the Cornell Scale for Depression in Dementia (CSDD) [22] and the Geriatric Depression Scale (GDS), and (3) any notes made by the nursing home doctor regarding the presence of depression or depressive symptoms. In addition, notes regarding depression in the nurses' documentation 
Iden et al.: Prevalence of Depression among Recently Admitted Long-Term Care

Patients in Norwegian Nursing Homes

system were retrieved but not considered as diagnostic initiatives. For patients treated with antidepressant drugs, we registered when and why medication was started, and any change of drug treatment after admission to nursing home. Nonpharmacological therapy for depression was recorded as well.

Immediately after carefully having studied the patients' medical records, the first author (K.R.I.), a GP, conducted individual interviews with all patients in order to diagnose depression according to the criteria of ICD-10. In addition, we applied the Major Depression Inventory [23] in order to rate the severity of depression. Thus, this scale was not used to diagnose depression; therefore, the validity is of less importance. Occasionally, the patients' close relatives or primary nurse took part in the interviews. The diagnosis of depression was based both on interviews and diagnostic information from medical records. We compiled all diagnoses of F32-34 (ICD-10) into a common diagnosis labeled 'depression'.

Immediately after having compiled the diagnosis of depression for each patient, the GP completed the CSDD in collaboration with the patients' primary nurse. The CSDD is validated for both patients with and without cognitive impairment, showing high interrater reliability and fairly good validity among Norwegian nursing home patients [24]. The scale comprises 19 questions with the possible scores 0 (absent), 1 (moderate), and 2 (severe). The total score ranges from 0 to 38; scores of $\geq 8$ indicate depression; a score $>12$ indicates severe depression.

The interview of the patients' primary nurse also comprised the Clinical Dementia Rating (CDR) scale [25]. The CDR scores range from 0 (no dementia), to 0.5 (mild cognitive impairment), 1 (mild dementia), 2 (moderate dementia), and 3 (severe dementia). The scale has been validated for nursing home patients in Norway. Scores of $\geq 1$ indicate dementia with a very high sensitivity and specificity [26].

The Lawton and Brody Instrumental Activities of Daily Living (IADL) [27] scale was completed by the patients' primary nurse. The IADL scale comprises 8 items with possible scores of 0 (not able to evaluate) and 1 (normal functioning), whereas increasing values from 2 to 5 indicate functional impairment in terms of everyday activities. The total score ranges from 8 to 31 .

Ethics

The study was approved by the Western Regional Committee for Medical and Health Research Ethics (2011/537). Written consent was obtained from patients or next-of-kin for patients with cognitive impairment. Nine patients were able to provide their own consent to participate.

Statistical Analysis

Data were analyzed using IBM SPSS Statistics 18 (PASW Statistics for Windows, SPSS Inc., Chicago, Ill., USA). We investigated all variables for normality using histograms and Q-Q plots. To explore the relationship between categorical data, we used the $\chi^{2}$ test for independence. In case of numbers smaller than 5 , we used Fisher's exact test. For correlation analysis on continuous variables, we used the Pearson product-moment correlation coefficient.

\section{Results}

\section{Demography and Dementia}

A total of 88 patients were included, with a mean (SD) age of 86.9 (8.0) years for men and 86.2 (7.2) years for women; $58.9 \%$ of the patients were women (table 1 ). The median (range) time from LTC admission to assessment for depression was 50 (6-128) days. According to the CDR, 69/88 (78.5\%) patients suffered from dementia (CDR score $\geq 1$ ). The median (range) IADL score was 27 (9-31) (table 1). There was a strong positive correlation between IADL and CDR scores $(\mathrm{r}=0.53, \mathrm{p}<0.001)$.

\section{Depression}

Symptoms of depression were evaluated according to the research criteria of ICD-10. Of the 88 patients, $63(71.6 \%)$ were not depressed, 15 (17.0\%) had mild, 5 (5.7\%) had moderate, and $5(5.7 \%)$ had severe depression. The prevalence of depression did not differ significantly between the 35 patients who were evaluated within 6 weeks after admittance and those 52 evaluated after 6 weeks of stay [11/35 (31.4\%) vs. 14/52 (29.6\%), $p=0.65]$. 
Dementia

Cognitive Disorders

Table 1. Patient characteristics

\begin{tabular}{l|l}
\hline \multicolumn{2}{l|}{ Dement Geriatr Cogn Disord 2014;37:154-162 } \\
\hline DOI: $\underline{10.1159 / 000355427}$ & $\begin{array}{l}\text { C 2013 S. Karger AG, Basel } \\
\text { www.karger.com/dem }\end{array}$ \\
\hline
\end{tabular}

Iden et al.: Prevalence of Depression among Recently Admitted Long-Term Care Patients in Norwegian Nursing Homes
$86.4 \pm 7.4$

$56(58.9)$

58 (65.9)

21 (23.9)

7 (7.9)

$2(2.3)$

$50(6-128)$

$10(11.4)$

$9(10.2)$

27 (30.7)

$32(36.4)$

$10(11.4)$

$27(9-31)$

Values represent $\mathrm{n}(\%)$, mean \pm SD or median (range).

Table 2. Prevalence of depression in recently admitted nursing home patients, according to ICD-10 criteria, and nursing home doctors' diagnostic workup documented in patients' medical records

\begin{tabular}{|c|c|c|c|c|}
\hline \multirow{2}{*}{$\begin{array}{l}\text { Documentation in patients' medical } \\
\text { record }\end{array}$} & \multicolumn{4}{|c|}{ Patients assessed for depression (ICD-10), n (\%) } \\
\hline & $\begin{array}{l}\text { all } \\
(\mathrm{n}=88)\end{array}$ & $\begin{array}{l}\text { depression (ICD-10) } \\
(\mathrm{n}=25)\end{array}$ & $\begin{array}{l}\text { no depression (ICD-10) } \\
(n=63)\end{array}$ & $\begin{array}{l}\chi^{2} \\
\mathrm{p} \text { value }\end{array}$ \\
\hline Any diagnostic initiative ${ }^{\mathrm{a}}$ & 33 & $14(56.0)$ & $19(30.2)$ & 0.02 \\
\hline Diagnostic code $\mathrm{e}^{\mathrm{b}}$ & 17 & $8(32.0)$ & $9(14.3)$ & $0.08^{\mathrm{c}}$ \\
\hline Diagnostic test $\mathrm{t}^{\mathrm{d}}$ & 3 & $1(4.0)$ & $2(3.2)$ & $1.00^{\mathrm{c}}$ \\
\hline Nursing home doctors' note & 25 & $10(40.0)$ & $15(23.8)$ & 0.13 \\
\hline
\end{tabular}

${ }^{a}$ Comprising diagnostic code, diagnostic test and doctors' note. ${ }^{\mathrm{b}}$ Diagnostic code: F41.2 (mixed anxiety and depressive disorder) from the ICD-10; P03 (depressed mood) and P76 (depressive disorder) from the ICPC-2 (International Classification of Primary Care, second version). ${ }^{\mathrm{c}}$ Fisher's exact test. ${ }^{\mathrm{d}}$ CSDD and GDS.

Screening of the study population by means of the CSDD revealed a mean (SD) sum score of 5.9 (4.3). Altogether, 27/88 (30.7\%) patients had scores of $\geq 8$ and were considered depressed. More patients with an ICD-10 depression diagnosis, compared to those with no depression, had a CSDD sum score $\geq 8$ [18/25 (72\%) vs. 9/63 (14.3\%) patients, $p<0.001]$.

There was no significant difference in the prevalence of depression between patients with $[23 / 69(33.3 \%)]$ and without dementia $[2 / 19(10.5 \%)](p=0.08)$.

\section{Review of the Nursing Home Records}

Review of the patients' medical records revealed that any diagnostic initiatives, that is notes written by nursing home doctors, diagnostic codes and diagnostic tests regarding depression, were documented for $14 / 25$ (56\%) of the patients with depression and for 19/63 $(30.2 \%)$ of those not depressed $(p=0.024)$ (table 2$)$. Diagnostic tests conducted after nursing home admission were documented in the medical records of 3 patients (CSDD: $\mathrm{n}=2$; GDS: $\mathrm{n}=1$ ). Among patients with depression, diagnostic workup was less commonly documented for patients with dementia [15/23 (65.2\%)] than for those without dementia [2/2 (100\%)]; however, these numbers were too small for comparison. Nurses documented depression for 
Iden et al.: Prevalence of Depression among Recently Admitted Long-Term Care Patients in Norwegian Nursing Homes

Table 3. Indications for prescribing antidepressant medications to recently admitted nursing home patients, and depression according to ICD-10

\begin{tabular}{lllll}
\hline $\begin{array}{l}\text { Indication for } \\
\text { antidepressant use }\end{array}$ & \multicolumn{4}{l}{ Patients using antidepressants, $\mathrm{n}(\%)$} \\
\cline { 2 - 5 } & $\begin{array}{l}\text { all } \\
(\mathrm{n}=39)\end{array}$ & $\begin{array}{l}\text { depression (ICD-10) } \\
(\mathrm{n}=15)\end{array}$ & $\begin{array}{l}\text { no depression (ICD-10) } \\
(\mathrm{n}=24)\end{array}$ & $\begin{array}{l}\text { Fisher's exact } \\
\text { test } \mathrm{p} \text { value }\end{array}$ \\
\hline $\begin{array}{l}\text { Depression } \\
\begin{array}{l}\text { Neuropsychiatric } \\
\text { symptoms }\end{array}\end{array}$ & 20 & $11(73.3)$ & $9(37.5)$ & 0.05 \\
Unknown & 13 & $\begin{array}{l}2(13.3) \\
2(13.3)\end{array}$ & $\begin{array}{r}11(45.8) \\
4(16.7)\end{array}$ & 0.05 \\
\hline
\end{tabular}

Table 4. Antidepressants prescribed to recently admitted nursing home patients, according to indication and diagnostic initiatives

\begin{tabular}{lllll}
\hline $\begin{array}{l}\text { Any diagnostic } \\
\text { initiative }\end{array}$ & $\begin{array}{l}\text { Any antidepressant } \\
(\mathrm{n}=39)\end{array}$ & $\begin{array}{l}\text { Antidepressant for } \\
\text { depression, } \mathrm{n}(\%) \\
(\mathrm{n}=20)\end{array}$ & $\begin{array}{l}\text { Antidepressant for other } \\
\text { indications, } \mathrm{n}(\%) \\
(\mathrm{n}=19)\end{array}$ & $\begin{array}{l}\text { Fisher's } \\
\text { exact test } \\
\mathrm{p} \text { value }\end{array}$ \\
\hline $\begin{array}{l}\text { Yes } \\
\text { No }\end{array}$ & 26 & $\begin{array}{c}17(85.0) \\
3(15.0)\end{array}$ & $\begin{array}{r}9(47.4) \\
10(52.6)\end{array}$ & 0.019 \\
\hline
\end{tabular}

$15 / 25(60 \%)$ of those depressed according to ICD-10 and for 17/63 (27\%) of those not depressed $(\mathrm{p}=0.04)$.

\section{Treatment of Depression}

Altogether, 43/88 (48.9\%) patients received any treatment of depression: $24 / 88(27.3 \%)$ were treated with antidepressant medication only, 4/88 (4.5\%) received nonpharmacological treatment only (environmental interventions or talk therapy), and 15/88 (17.0\%) patients received antidepressants as well as nonpharmacological treatment.

Altogether, 39 patients were treated with antidepressants: 20/88 (22.7\%) for depression, $13 / 88(14.7 \%)$ for neuropsychiatric symptoms, whereas the indication for drug treatment was not documented in 6/88 (6.8\%) cases (table 3). Treatment with antidepressants was initiated before nursing home admission in 29/88 (33.0\%) patients and after admission in 10/88 (11.4\%). Antidepressants had not been withdrawn from any of the patients after admission. Of all patients, 26/88 (29.5\%) still received the same dose of antidepressants, whereas doses were reduced in 5/88 (5.68\%) and increased in 6/88 (6.8\%) patients; $2 / 88(2.3 \%)$ patients had their antidepressant replaced (not shown). Of the 20 patients receiving antidepressants for treatment of depression, 17/20 (85\%) had documented diagnostic initiatives in their medical records (table 4).

\section{Discussion}

This study found that depression affected $28 \%$ of recently admitted LTC patients, but in only half of the cases did we find evidence for a diagnostic evaluation of depression. Antidepressants were prescribed to $44 \%$ of the patients; however, only half of these patients were using these drugs for treatment of depression. 
Iden et al.: Prevalence of Depression among Recently Admitted Long-Term Care

Patients in Norwegian Nursing Homes

\section{Prevalence of Depression}

Even though there are many differences in the diagnostic criteria used, it is well established that the prevalence of depression among nursing home patients is high [28]. Patients recently admitted to a nursing home are especially at risk of developing depression due to severe functional impairment, multimorbidity, cognitive impairment, expectations to adjust, and finally mourning and losses [1]. Some studies have pointed out that relocation per se increases the risk of depression $[2,6]$. To our knowledge, there are only a few studies that shed light on the prevalence of depression among these patients. A Dutch study conducted within 10 days after admission found $27 \%$ of the patients having depressive symptoms [29], assessed with the Minimum Data Set Depression Rating Scale [30]. An American study revealed a prevalence rate of $33 \%$ on admission and a $40 \%$ cumulative prevalence rate during the first 3 months [4], according to quarterly Minimum Data Set assessment. Clinical interviews with Australian nursing home patients, considering the DSM-IV criteria and CSDD, revealed a 25 and $14 \%$ prevalence of major depression 1 and 3 months after admission, respectively [31]. After completion of the transmission process itself, one may expect a gradual adaptation to the nursing home environment. We found no statistically significant difference in depression prevalence between patients assessed within 6 weeks versus more than 6 weeks after admission. This may, however, be due to the small sample size and should therefore be interpreted with care.

Across different diagnostic criteria, the $28 \%$ prevalence rate found in our study compares well to other studies that are based on depression assessment scales. Differences in admission criteria and case mix between nursing homes in various countries may also contribute to different prevalence rates. The prevalence of depression did not differ significantly between patients with and without dementia. This finding is in line with another recently published study by van Asch et al. [18].

For $30 \%$ of the patients who were not depressed on our systematic assessment, some diagnostic initiative was documented in the medical records (table 2). However, we were not able to examine the quality of the diagnostic process performed by the nursing home doctors compared to the known systematic procedure by the study researcher, and hence the equivalence of the resulting depression diagnoses.

\section{Diagnosing Depression}

Our study revealed that surprisingly little attention was paid to diagnostic workup and documentation of depression in the medical records of recently admitted LTC patients. We found that $19 \%$ of all patients had a diagnostic code regarding depression documented in their medical records. A Dutch study reported a $10 \%$ prevalence of diagnosed depressive disorders [18] in nursing home populations. Neither we nor van Asch et al. [18] found a significant difference in diagnostic workup between patients with and without dementia.

Diagnostic tools such as CSDD and GDS were documented for only 3 patients; this finding supports a qualitative study [19] suggesting that nursing home doctors hardly ever perform screening tests for depression. Even though diagnostic tools can be assumed to be known by nursing home doctors, these tests may not be easily available in all nursing homes due to different electronic patient record systems. Another study suggests that doctors focused less on depression than nursing staff [32]. In the medical records, we found doctors' notes regarding depression in $40 \%$ and nurses' notes in $47 \%$ of those depressed. Even though the nurses pay more attention to patients' depressive symptoms, their accuracy in diagnostics is limited [32, 33]. We can only speculate about the reasons for the doctors' diagnostic inaction. A previous study suggests that nursing home doctors base their diagnostic and therapeutic conclusions about depression on entrusted nurses' opinions [19]. Provided the limited time that doctors have, high-quality cooperation with the nursing staff is needed to safeguard the patients' mental health $[34,35]$. Registration of the patients' weight and body mass index is 
Iden et al.: Prevalence of Depression among Recently Admitted Long-Term Care

Patients in Norwegian Nursing Homes

mandatory in Norwegian nursing homes and may assist the staff in focusing on the patients' nutrition and well-being. In the same manner, compulsory psychiatric screening should be conducted in all patients within a short time after admission and later on a regular basis. For this purpose, the ICD-10 diagnostic system is too time-consuming and complicated for most nursing home doctors to complete. Further, patients with severe dementia or aphasia are not eligible for individual interviews. A validation study [24] indicates that CSDD is a suitable screening tool in the Norwegian nursing home setting. In order to improve the systematic diagnostics of depression, we believe that it is worthwhile to implement tools that fit patients irrespective of their mental states.

\section{Treatment}

Our study showed that $44 \%$ of the recently admitted patients received antidepressants, compared to $30 \%$ of patients with dementia and $27 \%$ of those without on admission to Swiss nursing homes [36]. The considerably higher antidepressant use in our study can only partly be explained by the fact that patients were assessed within a period of 3 months after admission, because treatment with antidepressants was initiated before admission for 3 out of 4 patients. This finding supports previous research indicating that the prescription of antidepressants increases after nursing home admission [37]. The extensive use of antidepressants among recently admitted nursing home patients reflects the prescribing trends for the general population in Norway, that is $13 \%$ of persons aged 80 years and older are using these drugs [38].

In recent decades, there has been an encouraging decline in the prescription of antipsychotic drugs to Norwegian nursing home patients. On the other hand, increased prescription of antidepressant drugs seems to have partly replaced antipsychotics [9]. The most obvious explanation may be that nursing home doctors increasingly prescribe antidepressant medications for other indications than depression. We found that every third prescription of antidepressants was for treatment of neuropsychiatric symptoms. Although a literature review indicates that this treatment can be effective [39], neuropsychiatric symptoms are not approved as an indication for antidepressants. However, a full discussion of this issue is beyond the scope of this paper.

Almost all patients using antidepressants for treatment of depression had some documentation on the diagnosis of depression or diagnostic initiatives in their medical records. Even though initiating these drugs seems to be justified, prescribing antidepressant medication to vulnerable old nursing home patients should always be thoroughly evaluated considering limited efficiency $[11,12]$ and risk of serious side effects $[14,15,17]$. Nonpharmacological treatment options should always be the first choice. Our study revealed that $34.9 \%$ of the patients received nonpharmacological interventions for depression, which is not a small proportion after all. Psychosocial interventions, such as psychotherapy, music therapy, reminiscence therapy, and physical training programs, should be implemented in nursing homes at a larger scale. However, so far only a few studies have explored the efficiency of nonpharmacological treatment $[7,40,41]$, and comparative studies are lacking.

\section{Methodological Considerations}

Recently admitted nursing home patients to LTC are a vulnerable group, which has not been included in many previous studies. The strength of this study is that an experienced GP performed a comprehensive diagnostic procedure; however, her findings have not been verified by another doctor. The medical record for each patient had been reviewed thoroughly before she conducted interviews with all patients. Because she was not aware of the nurses' diagnostic assessment regarding depression (CSDD) when diagnosing depression according to ICD-10, and vice versa, we were able to compare doctor-led and nurse-led diagnostic workup among patients at particular risk. The participating institutions were of 
Iden et al.: Prevalence of Depression among Recently Admitted Long-Term Care

Patients in Norwegian Nursing Homes

different sizes and located both in a city and in smaller municipalities. Hence, they are representative of Norwegian nursing homes in general.

The most important limitation of the study is the small sample size, with consequences for statistical power. The patient variables were recorded within a time range of 3 months after admission. Because both the prevalence of depression [4] and the prescription of antidepressants [37] tend to increase during the initial phase of nursing home stay, data collection and assessment of all patients should preferentially have been conducted after similar lengths of stay. However, this was impossible for practical reasons.

\section{Conclusion}

Although depression was prevalent in recently admitted LTC patients, documented diagnostic initiatives were sparse after admission. Antidepressants were prescribed for many patients, but in only half of the cases was the indication treatment of depression. Screening tools for depression which can be applied by trained nurses should be mandatory on admission.

\section{Acknowledgement}

This study was supported by a fund for Research in General Practice, Norwegian Medical Association.

\section{Disclosure Statement}

The authors have no conflicts of interest to declare.

\section{References}

1 Djernes JK: Prevalence and predictors of depression in populations of elderly: a review. Acta Psychiatr Scand 2006;113:372-387.

2 Anstey KJ, von Sanden C, Sargent-Cox K, Luszcz MA: Prevalence and risk factors for depression in a longitudinal, population-based study including individuals in the community and residential care. Am J Geriatr Psychiatry 2007;15:497-505.

3 Barca ML, Selbaek G, Laks J, Engedal K: Factors associated with depression in Norwegian nursing homes. Int J Geriatr Psychiatry 2009;24:417-425.

4 Hoover DR, Siegel M, Lucas J, Kalay E, Gaboda D, Devanand DP, Crystal S: Depression in the first year of stay for elderly long-term nursing home residents in the USA. Int Psychogeriatr 2010;22:1161-1171.

5 Gonzalez-Salvador T, Lyketsos CG, Baker A, Hovanec L, Roques C, Brandt J, Steele C: Quality of life in dementia patients in long-term care. Int J Geriatr Psychiatry 2000;15:181-189.

- 6 Pot AM, Deeg DJ, Twisk JW, Beekman AT, Zarit SH: The longitudinal relationship between the use of long-term care and depressive symptoms in older adults. Gerontologist 2005;45:359-369.

- 7 Konnert C, Dobson K, Stelmach L: The prevention of depression in nursing home residents: a randomized clinical trial of cognitive-behavioral therapy. Aging Ment Health 2009;13:288-299.

8 Selbaek G, Kirkevold O, Engedal K: The prevalence of psychiatric symptoms and behavioural disturbances and the use of psychotropic drugs in Norwegian nursing homes. Int J Geriatr Psychiatry 2007;22:843-849.

9 Ruths S, Sorensen PH, Kirkevold O, Husebo BS, Kruger K, Halvorsen KH, Selbaek G: Trends in psychotropic drug prescribing in Norwegian nursing homes from 1997 to 2009: a comparison of six cohorts. Int J Geriatr Psychiatry 2013;28:868-876.

10 Gaboda D, Lucas J, Siegel M, Kalay E, Crystal S: No longer undertreated? Depression diagnosis and antidepressant therapy in elderly long-stay nursing home residents, 1999 to 2007. J Am Geriatr Soc 2011;59:673680.

11 Banerjee S, Hellier J, Dewey M, Romeo R, Ballard C, Baldwin R, Bentham P, Fox C, Holmes C, Katona C, Knapp M, Lawton C, Lindesay J, Livingston G, McCrae N, Moniz-Cook E, Murray J, Nurock S, Orrell M, O’Brien J, Poppe M, Thomas A, Walwyn R, Wilson K, Burns A: Sertraline or mirtazapine for depression in dementia (HTASADD): a randomised, multicentre, double-blind, placebo-controlled trial. Lancet 2011;378:403-411. 
Iden et al:: Prevalence of Depression among Recently Admitted Long-Term Care

Patients in Norwegian Nursing Homes

12 Boyce RD, Hanlon JT, Karp JF, Kloke J, Saleh A, Handler SM: A review of the effectiveness of antidepressant medications for depressed nursing home residents. J Am Med Dir Assoc 2012;13:326-331.

13 van den Brand MW, Pouwels S, Samson MM, van Staa TP, Thio B, Cooper C, Leufkens HG, Egberts AC, Verhaar HJ, de Vries F: Use of anti-depressants and the risk of fracture of the hip or femur. Osteoporos Int 2009;20: 1705-1713.

14 Coupland C, Dhiman P, Morriss R, Arthur A, Barton G, Hippisley-Cox J: Antidepressant use and risk of adverse outcomes in older people: population based cohort study. BMJ 2011;343:d4551.

15 Huybrechts KF, Rothman KJ, Silliman RA, Brookhart MA, Schneeweiss S: Risk of death and hospital admission for major medical events after initiation of psychotropic medications in older adults admitted to nursing homes. CMAJ 2011;183:E411-E419.

16 Sterke CS, Ziere G, van Beeck EF, Looman CW, van der Cammen TJ: Dose-response relationship between selective serotonin re-uptake inhibitors and injurious falls: a study in nursing home residents with dementia. Br J Clin Pharmacol 2012;73:812-820.

17 Bakken MS, Engeland A, Engesaeter LB, Ranhoff AH, Hunskaar S, Ruths S: Increased risk of hip fracture among older people using antidepressant drugs: data from the Norwegian prescription database and the Norwegian hip fracture registry. Age Ageing 2013;42:514-520.

18 van Asch IF, Nuyen J, Veerbeek MA, Frijters DH, Achterberg WP, Pot AM: The diagnosis of depression and use of antidepressants in nursing home residents with and without dementia. Int J Geriatr Psychiatry 2013;28: 312-318.

19 Iden KR, Hjorleifsson S, Ruths S: Treatment decisions on antidepressants in nursing homes: a qualitative study. Scand J Prim Health Care 2011;29:252-256.

20 Patterson BJ: The process of social support: adjusting to life in a nursing home. J Adv Nurs 1995;21:682-689.

21 The Norwegian Directorate of Health: http://helsedirektoratet.No/publikasjoner/nokkeltall-for-helsesektoren-2011/sider/default.aspx. 2012.

-22 Alexopoulos GS, Abrams RC, Young RC, Shamoian CA: Cornell scale for depression in dementia. Biol Psychiatry 1988;23:271-284.

-23 Olsen LR, Jensen DV, Noerholm V, Martiny K, Bech P: The internal and external validity of the major depression inventory in measuring severity of depressive states. Psychol Med 2003;33:351-356.

24 Barca ML, Engedal K, Selbaek G: A reliability and validity study of the Cornell scale among elderly inpatients, using various clinical criteria. Dement Geriatr Cogn Disord 2010;29:438-447.

25 Hughes CP, Berg L, Danziger WL, Coben LA, Martin RL: A new clinical scale for the staging of dementia. Br J Psychiatry 1982;140:566-572.

26 Nygaard HA, Ruths S: Missing the diagnosis: senile dementia in patients admitted to nursing homes. Scand J Prim Health Care 2003;21:148-152.

27 Lawton MP, Brody EM: Assessment of older people: self-maintaining and instrumental activities of daily living. Gerontologist 1969;9:179-186.

-28 Seitz D, Purandare N, Conn D: Prevalence of psychiatric disorders among older adults in long-term care homes: a systematic review. Int Psychogeriatr 2010;22:1025-1039.

29 Achterberg W, Pot AM, Kerkstra A, Ribbe M: Depressive symptoms in newly admitted nursing home residents. Int J Geriatr Psychiatry 2006;21:1156-1162.

-30 Burrows AB, Morris JN, Simon SE, Hirdes JP, Phillips C: Development of a minimum data set-based depression rating scale for use in nursing homes. Age Ageing 2000;29:165-172.

-31 McSweeney K, O’Connor DW: Depression among newly admitted Australian nursing home residents. Int Psychogeriatr 2008;20:724-737.

-32 Bruhl KG, Luijendijk HJ, Muller MT: Nurses' and nursing assistants' recognition of depression in elderly who depend on long-term care. J Am Med Dir Assoc 2007;8:441-445.

-33 Ayalon L, Arean P, Bornfeld H: Correlates of knowledge and beliefs about depression among long-term care staff. Int J Geriatr Psychiatry 2008;23:356-363.

-34 Davidson S, Koritsas S, O'Connnor DW, Clarke D: The feasibility of a GP led screening intervention for depression among nursing home residents. Int J Geriatr Psychiatry 2006;21:1026-1030.

35 McCabe MP, Davison T, Mellor D, George K: Knowledge and skills of professional carers working with older people with depression. Aging Ment Health 2008;12:228-235.

-36 Lustenberger I, Schupbach B, von Gunten A, Mosimann U: Psychotropic medication use in Swiss nursing homes. Swiss Med Wkly 2011;141:w13254.

-37 Nygaard HA: Duration of drug treatment in nursing homes. Tidsskr Nor Laegeforen 2001;121:1469-1471.

38 The Norwegian Prescription Database: http://www.Norpd.No/. 2011.

39 Henry G, Williamson D, Tampi RR: Efficacy and tolerability of antidepressants in the treatment of behavioral and psychological symptoms of dementia, a literature review of evidence. Am J Alzheimers Dis Other Demen 2011;26:169-183.

40 McSweeney K, Jeffreys A, Griffith J, Plakiotis C, Kharsas R, O’Connor DW: Specialist mental health consultation for depression in Australian aged care residents with dementia: a cluster randomized trial. Int J Geriatr Psychiatry 2012;27:1163-1171.

-41 Guetin S, Portet F, Picot MC, Pommie C, Messaoudi M, Djabelkir L, Olsen AL, Cano MM, Lecourt E, Touchon J: Effect of music therapy on anxiety and depression in patients with Alzheimer's type dementia: randomised, controlled study. Dement Geriatr Cogn Disord 2009;28:36-46. 